\title{
Estimation Risk of High Rise Building on Contractor
}

\author{
Imayanti Basari ${ }^{1}$
}

\begin{abstract}
The increasing need for space and limited land especially in big cities cause many high rise building projects in Indonesia. Construction projects including high rise building projects are located in complex and dynamic environments result in high levels of uncertainty and risk. Risks are always present in construction projects and often lead to delay schedules or cost overruns. Risk management is a process consisting of risk identification, qualitative and quantitative assessment, response with appropriate methods of handling and risk control. The concept of risk management is becoming very popular in a number of businesses. Many companies often create risk management procedures in their projects to improve performance, minimize losses and increase profits. Risk event from a different project is different from the risk event on another project. Likewise, the level of occurrence and impact in each project is always changing from one project to another. This makes it difficult for management to handle risks on new projects. Lack of risk management, even inadequate risk analysis, can put construction projects in jeopardy. This research looked for alternatives to get risk event, consequence or impact estimates and likelihood or generic possibilities in order to be used to control the risk of subsequent high rise building projects. This research involves several high rise building projects that will be used as a basis for determining risk events, consequence or impact and likelihood or possibilities. In this study used qualitative methods, and data analysis is done by statistical analysis by finding the average of available data. Estimation this risk can help contractors, especially in the field of high rise building to manage risk both from risk factors, likelihood and consequence.
\end{abstract}

Keywords_-Risk; Risk Event; Likelihood; Consequence.

\section{INTRODUCTION}

$\mathrm{T}$ The increasing need for space and limited land especially in big cities cause many high rise building projects in Indonesia. Special city of Jakarta there will be as many as 189 high-rise buildings or high rise until 2019. The multistory building under construction or construction stage includes apartments, hotels and offices. According to research by Colliers International Indonesia, of the total 113 buildings are apartments, 31 hotels and 45 offices. The details, in the fourth quarter until the end of 2016 there will be 25 apartment buildings handed over to its customers, 11 publicly opened hotels, and 14 office buildings in operation.

Construction projects including high rise building projects are in complex and dynamic environments that create uncertainty and high risk, coupled with time-consuming constraints. As the most common and typical project type, the construction project has several characteristics such as deadlines, special objects, financial constraints and economic requirements, organizational conditions and special laws, systematic complexity and characteristics.

For that every construction project itself is a complex system. Risk always exists in construction projects and often leads to delay schedules or cost overruns. Risk management is a process that consists of risk identification, qualitative and quantitative assessment, response with appropriate methods of handling and risk control.

\footnotetext{
${ }^{1}$ Imayanti Basari is with Master Program in Technology Management, Institut Teknologi Sepuluh Nopember Surabaya Surabaya, Indonesia. Email: imay1_sari1@yahoo.com.
}

The concept of risk management has become very popular in a number of businesses. Many companies often create risk management procedures in their projects to improve performance, minimize losses and increase profits [1].

Risk event from a different project is different from the risk event on another project. Likewise, the level of occurrence and impact in each project is always changing from one project to another. This makes it difficult for management to handle risks on new projects. Lack of risk management, even inadequate risk analysis, can put construction projects in jeopardy.

The worthwhile benefit of problematic projects is the opportunity to learn from the problem. But the people who have been involved in the matter often forget quickly. This is a waste of experience because the lessons we can take on the issue can help us improve our knowledge and help us avoid the same problems in subsequent projects [2].

Based on observations and coordinate report data in 2016 found several problems in high risk building projects such as large accounts receivable due to owner delay pay progress payment and profit decrease due to error production in the field.

From the description above it is found the need to determine the risk event in general (generic) on the high rise building project and estimate the risk of each risk event. 


\section{METHOD}

\section{A. General Overview}

Definition of Risk according to AS/NZS 4360:2004 "the chance of something happening that will have an impact on objectives".

While risk management is a system that aims to identify all risks involved in business or project activities that can be used to address how to manage risk, the risk management process framework has several stages ranging from risk identification, risk classification, risk analysis, mitigation and Risk management. The objectives of risk management are as follows [3]:

1. Limit the possibilities of uncertainty

2. Make steps that lead to more proactive action than reactive in view of the possibility of great threats and losses.

3. Limit losses and uncertainty to stakeholders

4. Maintaining continuity of the operation program, so as not to be disturbed by events that have not been previously anticipated.

5. Run an effective risk management program so as to have a beneficial effect and not incur new costs.

The usefulness of risk management in the tender stage includes:

1. Identify possible risks with reference to previous experiences.

2. Create a mitigation plan if the identified risks are actually occurring.

3. Calculate the cost effects that need to be included in the tender price.

4. Provide guidance to the project team who will carry out their duties to make plans for risk mitigation.

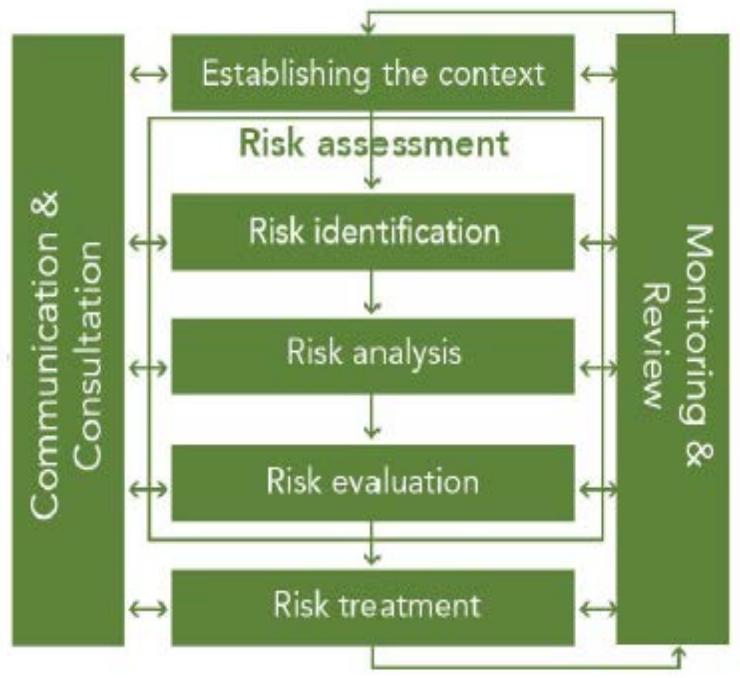

Figure 1. Risk Management Procedure (AS/NZS 4360)

Risk management has three main stages: risk identification, risk analysis and risk management. The three main steps should be supported by valid data and good communication between the highest leadership to the lowest level workers in the organizational structure so that the risk management system can run well so that the risk is considered to be detrimental can be reduced.

\section{1) Risk Identification}

Complete identification uses a structured systematic process, since a potential risk identified at this stage may not be included from further analysis. Identification includes all risks, either under the control of the organization or not. Risk identification is useful for knowing which risks might affect the project and to document its characteristics. Risk identification is a continuous process, as there may be new risks to be discovered throughout the project. Broadly speaking there are two categories of risks: internal and external risks. Internal risk is the risk that comes from the company or the project itself. Examples: cost, productivity, contract, turnaround time, etc. While the external risk is the risk originating not from the company or project Example: political conditions, inflation etc.

\section{2) Risk Analysis}

Broadly speaking there are two kinds of ways to perform risk analysis, namely qualitatively and quantitatively. Analytical analysis is qualitatively used to matters that cannot be calculated materially for example is a disruption of comfort in the community around the project while the analysis is quantitatively used on things that can be calculated mathematically such as material losses caused by the project. The goal is to separate acceptable risks with substantial risks, as well as to provide risk evaluation and risk data. Risk analysis considers the source of the risks, impacts and likelihood of such impacts. Risks are analyzed by combining estimated and likely impacts within the context of existing internal controls. The main factor in choosing a risk analysis technique depends on the type and size of the project, the information available, the cost of analysis, the time available to analyze, as well as the experience and expertise of the analyst [4].

a. Qualitative Analysis

This analysis can usually be done quickly and inexpensively, useful for setting priorities in risk mitigation planning, as well as being the basis for quantitative analysis if necessary. The basis for analyzing qualitatively among others is:

- Past project data from which the data can be studied what are the risks of the project.

- A clear scope of work will help to know what will be done to complete the project so that the risks it faces are also clear.

- Risk management plan in which there are regulations and responsibilities of each personnel involved in the project.

- List of risks that have been made at the risk identification stage

b. Quantitative Analysis

Performing a Quantitative Risk Analysis is a process of numerically analyzing the impact of the identified risk of the overall project objectives. The main benefit of this process is to generate quantitative risk information to support decisions and to reduce project uncertainty. Performing a Quantitative Risk Analysis is conducted against risks that have been prioritized by Qualitative Analysis. The Risk Analysis process has potential and substantially affects the demand for project competition. 
The Quantitative Analysis Process analyzes the impact of these risks on the project objectives. It is used primarily to evaluate the overall effect of all the risks that affect the project. If risk encourages quantitative analysis, the process can be used to assign numerical priority ratings to those risks individually.

\section{3) Risk Management}

Risk management involves identifying various options to deal with risks, assessing those options, developing risk control plans and monitoring and risk control.
a. Risk Control Planning
Consists of:
- Risk Avoidance,
- Risk Reduction,
- Risk Transfer,
- Risk Maintain.

b. Risk Monitoring and Control

Steps that can be done among others:

- Monitoring \& Review

- Communication and Consultation

- Documentation

\section{B. Risk Assessment by Mean Method (Average)}

The probability value of an event A, written $P$ (A) is defined such that:

$$
0 \leq \mathrm{P}(\mathrm{A}) \leq 1
$$

$\mathrm{P}(\mathrm{A})=0$, if $\mathrm{A}$ impossible to happen

$\mathrm{P}(\mathrm{A})=1$, if $\mathrm{A}$ must be happen where :

$$
P(A)=\frac{n(A)}{n(S)} \times 100 \%
$$

Statistical Estimation (Average Population Confidence Interval). If given a small sample $(\mathrm{n}<30)$ but taken from a population with a normal distribution and no population variance, then the variance of the S2 population can be used instead of $\sigma 2$, but the distribution used is the student $t$ distribution. If the sample average is xs, then the confidence interval $100(1-\alpha) \%$ for the average population $\mu$ will be provided by:

$$
\bar{x}-t_{\alpha / 2} \frac{s}{\sqrt{n}}<\mu<\bar{x}+t_{\alpha / 2} \frac{s}{\sqrt{n}}
$$

where :

$$
\begin{array}{ll}
\mathrm{n} & =\text { Number of samples } \\
\bar{x} & =\text { Average value or Mean } \\
\mathrm{S} & =\text { The value of standard deviation } \\
100(1-\alpha) \% & =\text { Prediction interval (for the example if } \\
& \text { prediction interval }=95 \%, \text { so } \alpha=0.05) \\
\text { Df } & =\text { n- } 1=\text { degree of freedom } \\
\mathrm{t}_{\alpha / 2} & =\text { obtained from table distribution } \mathrm{t}
\end{array}
$$

That the average n-sized sample will lie between $-t_{\alpha / 2}$ and $\mathrm{t}_{\alpha / 2}$ :

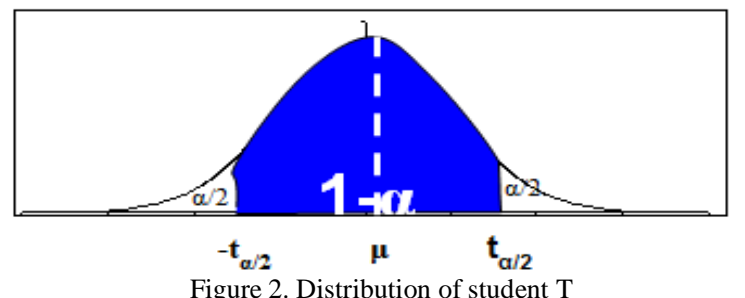

With probability:

$$
\mathrm{P}\left(-\mathrm{t}_{\alpha / 2}<\mathrm{Z}<\mathrm{t}_{\alpha / 2}\right)=1-\alpha
$$

Where the variable $\mathrm{t}$ is :

$$
T=\frac{\bar{x}-\mu}{S / \sqrt{n}}
$$

$t_{\alpha / 2}$ is the variable value of $t$ with the right tail area $\alpha / 2$.

\section{RESEARCH METHOD}

This research is a qualitative research with mean value. Methods of data collection is the way used by researchers in collecting research data. This research starts from the process of collecting supporting data from several high rise building projects where the data to be collected is secondary data from risk register and risk assessment. These data are obtained from the risk and development division of PT Adhi Karya and PT Adhi Persada Gedung.

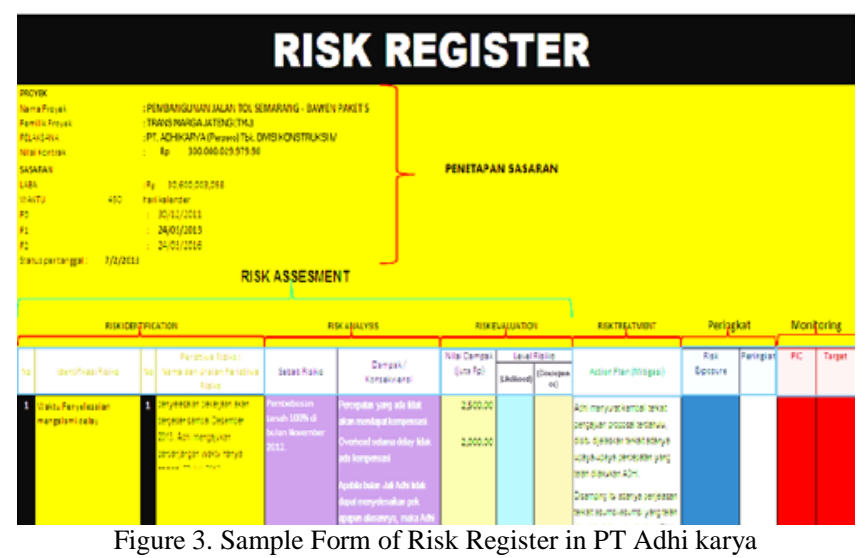

The tools used in data analysis are tailored to the purpose of the study. Based on the research flow as outlined in Figure IV, it is explained that this research starts from literature study process then formulation of problem, looking for risk event, sorting risk level from each factor, calculating likelihood average and consequence with supporting data from risk report Assessment of several high rise building projects then the data is processed so as to derive conclusions as a result of the research.

To determine risk from risk event, the possibility and impact of risk in high rise building projects hence used secondary data risk assessment from each project and also for data processing done by using descriptive analysis method using mean calculation from existing data so that The resulting data can be used by the contractor to manage risk on subsequent projects. 


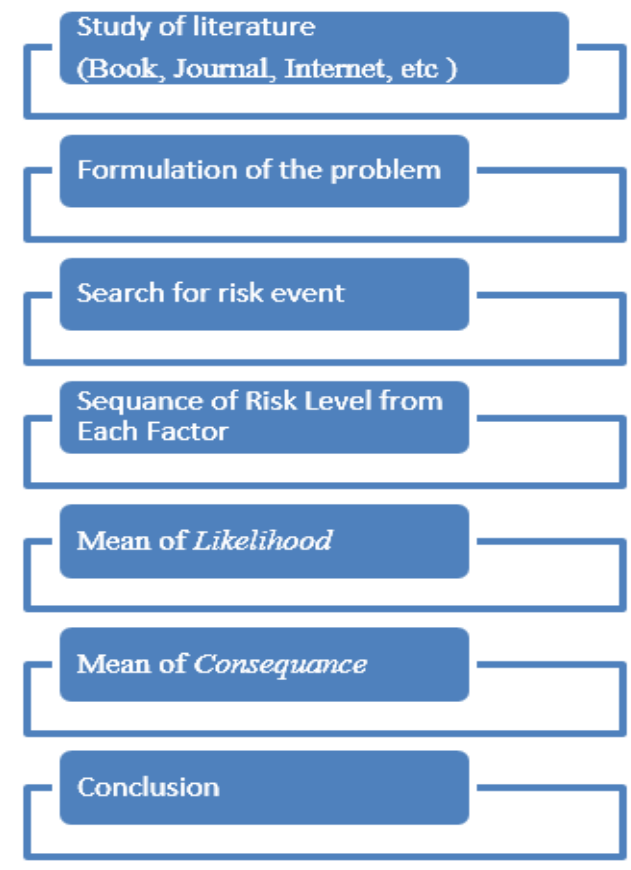

Figure 4. Research Flow Chart

There are several steps done in this research as follows:

\section{A. Search for Risk Event}

From the literature review used obtained data grouped in 76 risk variables.. Risk events from the literature review mentioned above are interpreted based on the definition of risk where risk according to the risk / risk is the possibility of something that will have an impact on the goal. Based on the above definition, the risk event is reduced to table I

TABLE 1.

DATA RISK EVENT

\begin{tabular}{cl}
\hline No & \multicolumn{1}{c}{ Variable } \\
\hline 1 & Engineer clarify differences in document based on the highest price \\
2 & Late contract issuance \\
3 & Handover field on hold \\
4 & Contractor Failure to meet its obligation due to internal factors \\
5 & Error of field data interpretation during tender \\
6 & Site information error from MK \\
7 & The existence of physical conditions that cannot be predicted before \\
8 & Material approval process is late due to mistake of the CM \\
9 & Owner push too tight a schedule \\
10 & Error execution methods contained in the contract \\
11 & Extension of time due to owner and weather factors denied \\
12 & Extension of time due to variation denied \\
13 & Contractor must implement any variation instruction \\
14 & Variation claims due to government policy on fuel prices are denied \\
15 & Basic price estimation error \\
16 & Owner failed to pay due to financial \\
17 & Owner refuse to pay interest on the delay \\
\hline \hline
\end{tabular}

\section{B. Probability (likelihood) of Risk}

Estimates the likelihood of the risk events that have been obtained above with existing secondary data using the mean niali (mean) analysis. The quantitative criteria for probability (likelihood) can be seen from the following table II where five possible ratings are used.
TABLE 2.

LIKELIHOOD SCALE - 5 RATING

\begin{tabular}{lll}
\hline \hline LIKELIHOOD & 1 YEAR & \multicolumn{1}{c}{ CRITERIA } \\
\hline Almost Never & $0-20 \%$ & It will be very unlikely to happen \\
Unlikely & $21-40 \%$ & Minor possibility may occur \\
Possible & $41-60 \%$ & Equally likely between occur and not \\
Likely & $61-80 \%$ & Most likely it can happen \\
Almost Certain & $81-100 \%$ & It will certainly be possible \\
\hline \hline
\end{tabular}

\section{Consequance of Risk}

With the same calculations as in likelihood (probability) then the impact of the risk (consequence) using the mean (average). Reference to the determination of the value of the impact of the risk (consequence) as shown in table III as follows:

TABLE 3.

CONSEQUENCES SCALE - 5 RATING

\begin{tabular}{lcc}
\hline \hline CONSEQUENCES & \multicolumn{2}{c}{ EARNING (Rp) } \\
\hline MINOR & - & to 537.34 Millions \\
MODERATE & 538.34 & to 940.35 Millions \\
SEVERE & 941.35 & to $1,477.70$ Millions \\
MAJOR & $1,478.70$ to 2,686.72 Millions \\
CATASTROPHIC & \multicolumn{2}{c}{$>$ 2,686.72 Millions } \\
\hline
\end{tabular}

\section{RESEARCH FINDING AND DISCUSSION}

\section{A. Collection Data}

The data used is secondary data that is data obtained in the form of finished, processed and presented other parties in this case in the form of risk assessment reports from several high rise building projects as data sources. The data were obtained from each of the projects used as research samples. The samples used are 26 high rise building construction projects in progress.

Besides, it is also discussed about risk event data analysis, likelihood level and consequence of each sample to get the research objective that is to look for risk event happened to the project and to determine the risk of each risk event, to estimate the likelihood of risk Event and also predict the impact of the occurrence (consequence) of the risk event.

\section{B. Data Processing}

Tabulation of data is done for risk event data, likelihood level also levels of consequence. The data collected will be used to determine the risk event occurring in the project and determine the risk of each risk event, estimate the likelihood of the risk event and also estimate the impact of the risk event.

For data risk event the data that has been collected is included in tabulation with value 1 if the risk identification is present in the data sample and 0 if risk identification does not exist in the sample data. The number of risk identifiers divided by the total number of samples gives the percentage weight of each of the variables. Data event risk is said to be generic by assumption percentage value $>50 \%$.

\section{Determination of Generic Risk Event}

From the calculation of the data is taken percentage value above $50 \%$ as a determination of the generic risk event 
contained in high rise building projects for contractors. The bar chart of the calculation results can be seen in the picture.

From the calculation of the data is taken percentage value above $50 \%$ as a determination of the generic risk event contained in high rise building projects for contractors. The bar chart of the calculation results can be seen in the Picture V.

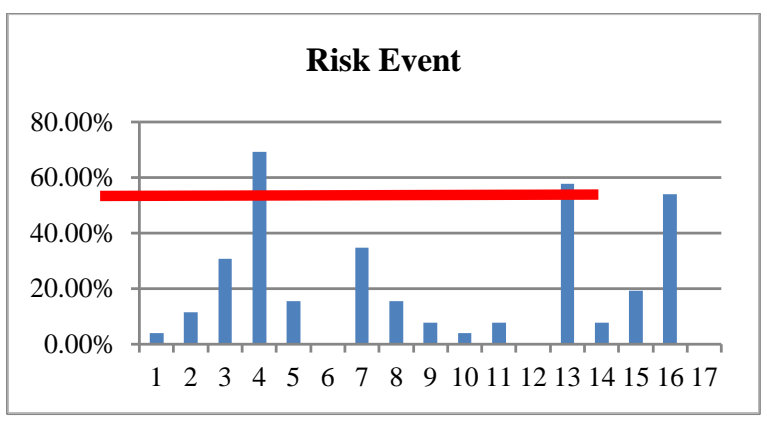

Figure 5. Risk Event Calculation Result

The result of determining risk event with percentage value $>50 \%$ is as follows:

TABLE 4.

RISK EVENT GENERIC

\begin{tabular}{|c|c|c|}
\hline NO & Variable & $\%$ \\
\hline 4 & $\begin{array}{l}\text { Contractor failure to meet its obligations due to } \\
\text { internal factors }\end{array}$ & $69.23 \%$ \\
\hline 13 & $\begin{array}{l}\text { Contractor must implement any variation } \\
\text { instructions }\end{array}$ & $57.69 \%$ \\
\hline 16 & Owner failed to pay due financial limitations & $53.85 \%$ \\
\hline
\end{tabular}

After weighing the risk event, 3 (three) values are taken probability $>50 \%$ of risk event are the failure of the contractor to fulfill its obligation due to internal factors, the contractor must implement all variation instructions, the owner fails to pay due to financial limitations.

The steps used to find the average population confidence interval using the student $t$ distribution. The distribution of the so-called student distribution was introduced in 1908 by William S. Gosset, an employee of Guinness Breweries, Ireland. In deriving this distribution, Gosset assumes that the sample is from a normal population, so that the curve form of the $t$ distribution such as the normal distribution curve, ie symmetric, has a lower side than the normal curve, which means the data tends to be further than the average.

Distribution $\mathrm{t}$ is used as almost for normal distribution with small sample size (usually $\mathrm{n} \leq 30$ ) and population deviation standard $(\sigma)$ is unknown.

For likelihood and consequence value is assumed at the same interval then percentage $\leq 1$. So for likelihood data with value 1 is assumed with value 0.2 , value $2=0.4$, value $3=0.6$, value $4=0.8$ and value $5=1$. This assumption applies also to value of consequence.

\section{CONCLUSIONS AND SUGGESTIONS}

\section{A. Conclusions}

Based on the results of research and processing of secondary data, the conclusions can be drawn as follow:

1. From the literature review Found 76 risk event, which based on the interpretation of the researcher to the definition of risk then the risk event is reduced to 17 risk event. Based on the prostate analysis, there are 3 risk events that have a weight of $>50 \%$ that is the failure of the contractor to fulfill its obligation due to internal factors, the contractor must implement all variation instructions, the owner fails to pay due to financial limitations.

2. For the mean value of likelihood to variable the failure of the contractor to fulfill its obligation due to internal factors are $0.4866<\mu<0.6245$, to variable the contractor must implement all variation instructions were $0.4703<\mu<0.6763$, while to variable the owner fails to pay due to financial limitations were $0.5684<$ $\mu<0.8031$.

3. Whereas the mean value of consequence to variable the failure of the contractor to fulfill its obligation due to internal factors are $0.3872<\mu<0.5684$, to variable the contractor must implement all variation instructions, the mean value of consequence were $0.3157<\mu<0.5909$ while to variable the owner fails to pay due to financial limitations were $0.4127<\mu<0.7016$.

Of the three variables above the value of the possibility and the greatest impact is on the variable owner failed to pay due to financial limitations. In this case to anticipate the risk event there are several mitigation has been done projects. For the failure variable contractors fulfill their obligations because internal factors require more effective and efficient planning in the procurement of materials, human resources both staff and labor, equipment, working methods and environment. As for service provider variables must implement any variation instruction need to be given limit of maximum value which can be done by contractor for example $15 \%$ from contract value, so if value of variation exceed $15 \%$ can be made new contract value. Whereas the failure variable the owner pays to include in the contract clause concerning the late payment fines of the owner and also the deadline contract clause maturity is permitted for the owner to delay payment so that if the owner exceeds the time limit the service provider (contractor) can stop his work in the compensation of Termination. dengan adanya kompensasi dari penghentian tersebut.

\section{B. Suggestions}

The author is aware of many deficiency in the results of this study, among others:

a. The process of obtaining risk event by eliminating the data using the definition of risk then for further research need a better study for risk management process from risk event until risk mitigation stage.

b. The data used only secondary data obtained from the assessment report of construction implementation.

c. With time constraints only review the risks of nonproject construction as a whole so that research can be done with the extent of risk management scope.

d. Data analysis is based only on the mean (average) value so that for further research can be developed with a more complete analysis either qualitatively or quantitatively. 
e. For other researchers who want to do research on risk management and project risk level can explore other construction areas such as infrastructure or investment projects.

\section{REFERENCE}

[1] P. K. Maheshbhai, R. Bhatt, and J. J. Bhavsar, "A Study of Risk Factors Affecting Building Construction Projects,” Int. J. Eng. Res. Technol., vol. 3, no. 12, pp. 831-835, 2014.
[2] R. M. Steinberg, F. J. Martens, M. E. A. Everson, and Nottingham Lucy E., "Enterprise Risk Management - Integrated Framework," COSO (Committee of Sponsoring Organizations of the Treadway Commission), 2004.

[3] C. F. Duffield and B. Trigunarsyah, Project Managemnet Conception to Completion:A unit for postgraduate courses. Melbourne: Engineering Education Australia, 1999.

[4] R. A. Euripides, "Troubled Projects In Construction Due to Inadequete Risk Management,” City University of Seattle, 2008. 